\title{
DETECTION OF LEPTOSPIROSIS AND LISTERIOSIS IN BOVINE ABORTION: AN IMMUNOHISTOCHEMICAL STUDY
}

\author{
V. MAHAJAN*, H. S. BANGA ${ }^{1}$, G. FILIA AND K. GUPTA ${ }^{1}$ \\ Guru Angad Dev Veterinary and Animal Sciences University \\ Ludhiana- 141 004, Punjab, India
}

The present study was conducted to decipher Leptospira and Listeria associated abortion in bovine using immunohistochemical techniques. Immuno-histochemical staining for antigens of Leptospira interrogans in fetal kidney revealed positive staining of organisms preferentially in lining tubular lumen and within tubular epithelial cells. Listerial antigen was identified as principally intracellular (in neutrophils and macrophages) evident as deep brown, short rods and/or clusters of organism(s) within the abscesses and area of necrotic foci. Immuno-histochemical method can be used as a rapid tool in the diagnosis of Leptospira and Listeria abortion cases.

Key words: Abortion, Immunohistochemistry, Leptospirosis, Listeriosis

Leptospirosis is a worldwide zoonotic disease caused by pathogenic Leptospira species. Infectious abortion caused by Leptospira species is a significant cause of reproductive failure resulting in enormous economic losses in bovine in tropical and subtropical countries (Elis, 1984). It particularly causes abortion and stillbirth in farm animals. Abortion may occur several weeks after infection of the dam will be the only evidence of the disease in this form (Adler and Moctezuma, 2010). Leptospira serovar hardjo is a potential cause of disease and should be considered when investigating cases of abortion, stillbirth, or atypical mastitis in dairy cows. ELISA has been described previously for detection of Leptospira serovar hardjo (Adler et al., 1982; Berchovich et al., 1990; Richardson et al., 1995; Theirmann and Garrett, 1983) in cows. Leptospirosis may be diagnosed by the presence of leptospiral antigens in tissue section (Ellis et al., 1983). Listeriosis is caused by a ubiquitous, zoonotic, intracellular pathogen Listeria monocytogens characterized by encephalitis, septicaemia and abortion in animals. Transmission of the disease occurs

*Corresponding Author

${ }^{1}$ Department of Veterinary Pathology, Guru Angad Dev Veterinary and Animal Sciences University, Ludhiana, Punjab 
through ingestion of feed contaminated with infected fetus, placenta or uterine discharge (Yaeger and Holler, 2007). Vertical transmission is the usual source of infection in ruminants, infections being transmitted transplacentally. L. monocytogenes gains access to the fetus by hematogenous penetration of the placental barrier. Abortion usually occurs in late pregnancy (after 7 months). Serological tests for the detection of antibodies have not been traditionally used for the diagnosis of listeriosis. A number of diagnostic tools have been tried and they have all been found to be largely unreliable, lacking sensitivity and specificity. Isolation of $L$. monocytogenes may require weeks and have low sensitivity (OIE, 2014). In this study, Immuno-histochemical technique was used for confirmation of $L$. monocytogenes and Dot ELISA was used for Leptospira serovar hardjo antibody detection in serum samples of aborted animals and immuno-histochemistry for the presence of leptospiral antigens in aborted fetal tissues from natural field (clinical) cases of bovine abortion.

\section{MATERIALS AND METHODS}

Tissue samples from the aborted fetuses of cattle and buffaloes $(n=21)$ and placental cotyledons $(n=14)$ were collected from cases of abortion at farms from various districts of Punjab in $10 \%$ neutral buffered formalin for routine histopathology. The tissue samples (lung, liver, kidney, brain) were dehydrated, cleared and embedded in paraffin sections ( $4-5 \mu \mathrm{m}$ thick) were cut and stained with haematoxylin and eosin
(H\&E) as per standard protocol (Luna, 1968). Blood sampling was possible only from 10 aborted animals from which aborted fetuses were also collected. The sera were separated and stored at $-20^{\circ} \mathrm{C}$ until they were tested for antibodies to Leptospira hardjo using ImmunoComb ${ }^{\circledR}$ Bovine Leptospira Antibody Test Kit (Biogal-Galed Labs, Israel)

For immuno-histochemical studies 4-5 $\mu \mathrm{m}$ thick paraffin embedded tissue sections were cut and mounted on Superfrost Plus, positively charged microscopic slides (Fisher Scientific, USA). Immunohistochemical staining was performed by using advanced SS ${ }^{\mathrm{TM}}$ One-Step PolymerHRP IHC Detection System (BioGenex Laboratories Inc., San Ramon, California, USA). A commercially available polyclonal antibody against Leptospira interrogans (ABD serotac) and Listeria monocytogenes (ABD serotac) were used in a dilution of 1:500. As negative control, sections were incubated with PBS instead of the primary antibody.

\section{RESULTS}

In the present study, out of ten serum samples collected from the aborted animals, two were positive for Leptospira serovar hardjo antibodies as analyzed by Dot ELISA. Moreover, gross and histologic changes in placenta were non-specific. Positive immunoreactivity was seen in kidney of two fetuses. Immunohistochemical staining for antigens of Leptospira interrogans in a formalin-fixed, paraffin-embedded kidney section of aborted fetus revealed positive staining of organisms lining tubular lumens and of antigens within tubular epithelial cells (Fig. 1). 
Indian Journal of Animal Health, December, 2018

\section{Detection of Leptospirosis and Listeriosis in bovine abortion}

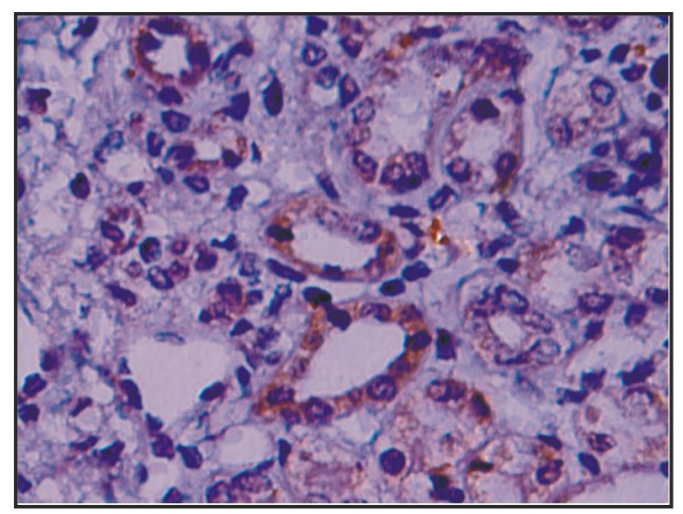

Fig. 1. Kidney: Immuno-reactivity to the anti- Leptospira polyclonal antibody (IHC-DAB- Gill's Haematoxylin counter stain $\mathrm{x} 100$ )

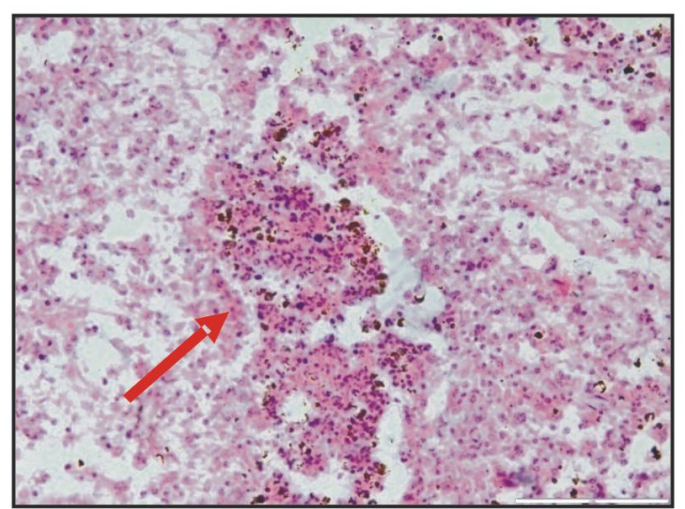

Fig. 3. Lung: Arrow showing abscess in aborted foetal lung (H \&E, 20X)

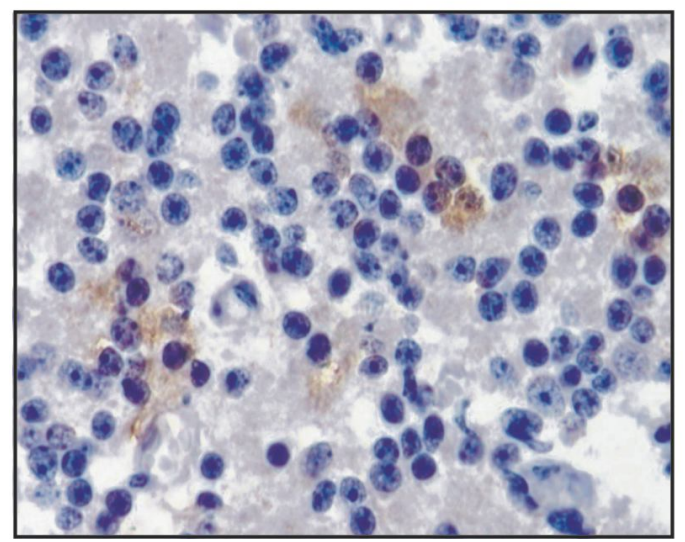

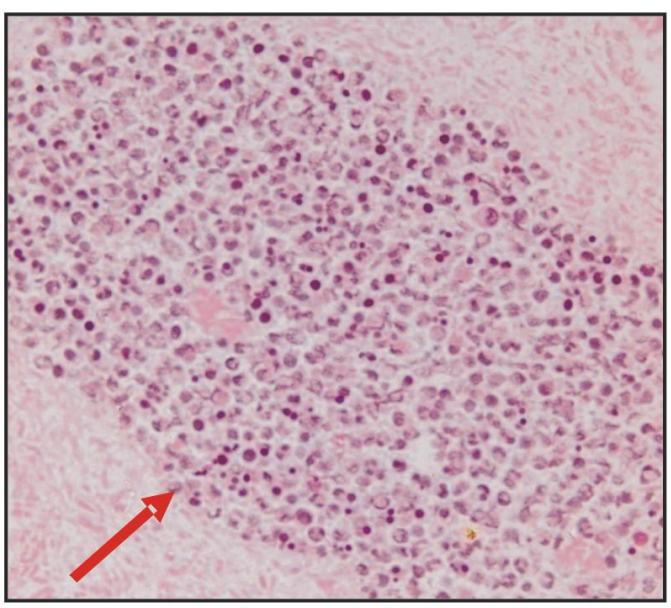

Fig. 2. Liver:Arrow showing abscess in aborted foetal liver (H \&E, 40X)

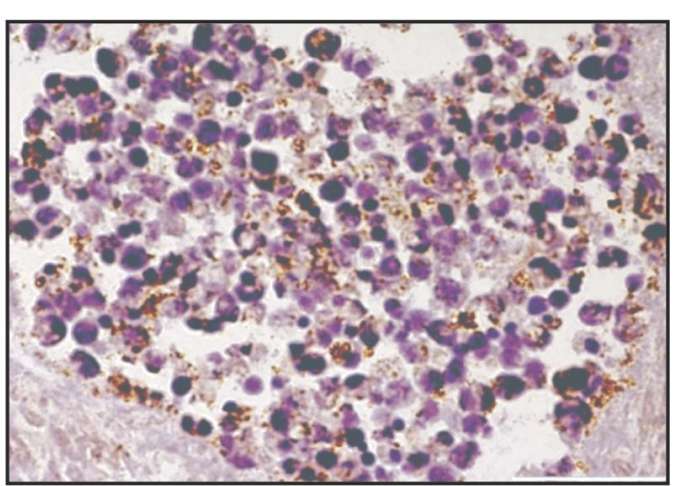

Fig. 4. Lung : Immuno-reactivity to the anti- Listeria monocytogenes polyclonal antibody with typical morphology of short rods in the abscess (IHC-DAB- Gill's Haematoxylin counter stain $x 100$ )

Fig. 5. Brain: Immunoreactivity to the anti-Listeria monocytogenes polyclonal antibody (100X) 
Listerial abortions were observed in four aborted fetuses at eighth month of gestation. Multifocal areas of abscesses and acute to sub-acute inflammation in liver and lung (Figs. $2 \& 3$ ) of aborted foetuses were observed. These foci have a central area of necrosis in which the organism can be visualized along with small numbers of degenerating neutrophils and mononuclear cells. Listerial antigen positive debris was identified as principally intracellular (in neutrophils and macrophages) deep brown short rods and clusters of organisms within abscess (Fig. 4) and necrotic foci in lung. In two of the aborted foetuse(s), glial nodules were seen in section of brain which showed immuno-reactivity to anti- Listeria monocytogenes polyclonal antibody (Fig. 5).

\section{DISCUSSION}

Diagnosis of leptospirosis is usually based on the demonstration of serum antibodies with serological test like the microscopic agglutination test (MAT) and enzymelinked immunosorbent assay (Levett, 2001). In the present study, Dot ELISA revealed two serum samples positive for Leptospira serovar hardjo antibodies collected from the ten aborted animals. Histopathological changes were observed mainly in the foetal kidneys where the organism arrives via the bloodstream. In the kidneys, the leptospira species multiplies, causing tubule-interstitial lesions (Scanziani et al., 1989). Immunoperoxidase staining of Leptospira spp. has been shown to be an accurate and reproducible technique to detect leptospiral antigen on formalin-fixed and paraffin-embedded tissues
(Ellis et al., 1983). Moreover, there is a positive correlation between results obtained from culture studies and results obtained from the IHC staining methods on infected tissues (Ellis et al., 1983). In the present study, leptospiral antigens intensely brown in color were detected in lining renal tubular lumen and within tubular epithelial cells by immunohistochemical techniques as reported earlier by various authors. (Ellis et al., 1983; Scanziani et al., 1989) Further, Saglam et al. (2008) found $11 \%$ of leptospiral antigen in kidney of aborted sheep foetuses by immunoperoxidase (IP) technique.

Confirmation of listerial infection in the laboratory is currently based on combined diagnostic assays like histological examination, immuno-histochemistry and bacteriological isolation (Gasanov et al., 2005; Low and Donachie, 1997). Isolation of $L$. monocytogenes may be unsuccessful even when appropriate samples are submitted as culture-negative cases can be associated with few or no bacteria in the lesions. Various authors demonstrated immunohistochemistry (IHC) as a helpful tool for diagnosis in natural cases of encephalitis (Johnson et al., 1995; Campero et al., 2002). In the present study, positive immunoreactivity to listerial antigen was seen in section of fetal lung, liver and brain (Fig. 5). Moreover, Weinstocks et al. (1995) described immunohistochemical testing useful in locating antigen in lesions with few bacteria or bacterial antigens in culture-negative cases for confirming the diagnosis of encephalitic listeriosis. 
It is concluded that immuno-histochemical method can be used as a rapid tool in the suspected leptospira and listera abortion cases, when isolation is not possible or

\section{REFRENCES}

Adler B, Cousins DV, Faine S and Robertson GM, 1982. Bovine IgM and $\mathrm{IgG}$ response to Leptospira interrogans serovar hardjo as measured by Enzyme Immunoassay. Vet Microbiol, 7: 577585

Adler B and Moctezuma A, 2010. Leptospira and leptospirosis. Vet Microbiol, 140: 287-296

Berchovich Z, Taaijke R and Bokhout BA, 1990. Evaluation of an ELISA for the diagnosis of experimentally induced and naturally occurring Leptospira hardjo infections in cattle. Vet Microbiol, 21: 255-262

Campero CM, Odeón AC, Cipolla AL, Moore DP and Poso MA et al., 2002. Demonstration of Listeria monocytogenes by immunohistochemistry in formalin-fixed brain tissues from natural cases of ovine and bovine encephalitis. J Vet Med B Infect Dis Vet Public Health, 49: 379-383

Elis WA, 1984. Bovine leptospirosis in the tropics: prevalence, pathogenesis and control. Prev Vet Med, 2: 411-421

Ellis TM, Robertson GM, Hustas L and Kirby M, 1983. Detection of leptospires in tissue using an immunoperoxidase staining procedure. Aust Vet J, 60: 364-367

Gasanov U, Hughes D and Hansbro PM, 2005. Methods for the isolation and identification of Listeria spp. and Listeria monocytogenes: a review. FEMS Microbiol Rev, 29: 851-875

Johnson GC, Fales WH, Maddox CW and Ramos-Vara JA, 1995. Evaluation of laboratory tests for confirming the diagnosis of encephalitic listeriosis in ruminants. J Vet Diagn Invest, 7: 223-228 material is fixed in formalin.

Conflict of interest: Authors declare that there is no conflict of interest regarding the present research work.

Levett PN, 2001. Leptospirosis. Clin Microbiol Rev, 14: 296-306

Low JC and Donachie W, 1997. A review of Listeria monocytogenes and listeriosis. Vet J, 153: 9-29

Luna LG, 1968. Manual of Histologic Staining Methods of the Armed Forces Institute of Pathology, $3^{\text {rd }}$ edn., (McGraw-Hill, New York)

Richardson GF, Spangler E and MacAulay EB, 1995. A serological survey of four Leptospira serovars in dairy cows on Prince Edward Island. Can Vet J, 36: 769-770

Saglam YS, Yenerb Z, Temurc A and Yalcinc E, 2008. Immunohistochemical detection of leptospiral antigens in cases of naturally occurring abortions in sheep. Small Ruminant Res, 74: 119-122

Scanziani E, Sironi G and Mandelli G, 1989. Immunoperoxidase studies on leptospiral nephritis of swine. Vet Pathol, 26: 442-444

Theirmann AB and Garrett LA,1983. Enzyme linked immunosorbent assay for the detection of antibodies to Leptospira interrogans serovar hardjo and pomona in cattle. Am J Vet Res, 44: 884-887

Weinstocks D, Horton B and Rowland PH, 1995. Rapid diagnosis of Listeria rnonocytogenes by immunohistochemistry in formalin-fixed brain tissue. Vet Pathol, 32: 193-195

Yaeger MJ and Holler LD, 2007. Bacterial causes of bovine infertility and abortion. In: Youngquist RS, Threlfall WR, editors. Current therapy in large animal theriogenology. 2nd edn., St. Louis: Elsevier. pp 389-399 